\title{
Home collection of urine specimens-boric acid bottles or Dipslides?
}

\author{
F E M Jewkes, D J McMaster, W A Napier, I B Houston, R J Postlethwaite
}

\begin{abstract}
Sterile mid stream specimens of urine (MSSU) were obtained from 84 children in a hospital outpatient department. All 84 children collected urine at home by one of two Dipslide methods and by collection into boric acid within 24 hours of the hospital collected MSSU. The samples collected at home were posted to the hospital. Thirty six of the Dipslides $(43 \%)$ and nine of the boric acid samples $(10 \%)$ were not sterile but none had a pure growth of a single organism of $>10^{5}$ organisms $/ \mathrm{ml}$. In addition, 17 of the Dipslides $(20 \%)$ were returned with one or both media detatched and therefore could not be relied upon to exclude urinary tract infection.

In a second part to the study, 95 urines which showed a significant growth in primary culture were also cultured after storage in boric acid. Inhibition was noted in nine samples after storage in boric acid, seven of which were in underfilled bottles. Transport of specimens in boric acid produced less contamination than Dipslides but may inhibit growth in a small number of specimens. Technical failures with Dipslides were disappointingly high.
\end{abstract}

The difficulties of home collection of urine specimens have long been appreciated and yet it remains an integral and essential part of paediatric practice. A combination of prolonged storage and transit time, often at room temperature rather than at $4^{\circ} \mathrm{C}$, is one of the major confounding problems. In 1969 Porter and Brodie first used boric acid as a preservative to transport urine specimens and found little contamination despite postal delivery. ${ }^{1}$ The results of Watson and Duerdin support this. ${ }^{2}$ Modified commercial methods based on boric acid are now also available and appear to show good preservation of samples. ${ }^{3}$ The dip-inoculum transport medium technique of transporting specimens first described by Mackey and Sandys in $1965^{4}$ now has wide usage in its commercial form as 'Dipslides' (Difco). It has also been shown to give reliable results in the diagnosis of urinary tract infection and has gained widespread support, particularly for use in general practice, ${ }^{5-8}$ where it provides a method for obtaining a positive urine result within 24 hours outside the hospital setting.

In this study we have tried to establish whether Dipslides, collected by two different techniques, or urine bottles containing boric acid, provide more accurate results when used at home compared with a carefully supervised hospital obtained mid stream specimen of urine (MSSU). Previous studies have suggested that there may be some inhibition of bacterial growth in boric acid solutions. ${ }^{12}$ In case the presence of boric acid produced false negative results, in a second part to the study we examined the effect of boric acid on the inhibition of bacterial growth.

\section{Patients and methods}

PART 1

One hundred and seven consecutive children (age range 2-18 years) attending the outpatient renal clinic were enrolled in the study. Only continent children participated. An MSSU was obtained from all children after perineal cleansing. The parents were instructed by experienced nursing staff to clean the perineum from front to back using $0.015 \%$ chlorhexidine with $0.15 \%$ cetrimide (Savlodil, ICI). Urine was stored immediately in a preservative free sterile container at $4^{\circ} \mathrm{C}$ before transfer to the laboratory for microscopy and culture on the same day.

Parents were instructed to clean the perineum in the same way before home urine collection. They were asked to collect the specimens on the same day as the hospital attendance. Detailed written instructions as to how to collect the samples were given to the parents in addition to a verbal explanation at the time of the clinic attendance.

The following three methods were used at home. (1) Boric acid. An MSSU was collected into a sterile bowl and $5 \mathrm{ml}$ poured into a bottle containing boric acid (Sterilin) to yield a $1 \cdot 3 \%$ solution. (2) Dipslide 'dip'. An MSSU was collected as above and a Dipslide was dipped into this. Excess urine was allowed to drain and the Dipslide was placed in the bottle and sealed. (3) Dipslide 'stream'. The Dipslide was held in the mid portion of the urinary stream, excess urine was allowed to drain and the slide was sealed in the bottle.

All children were asked to collect a boric acid sample. They were randomly allocated to collect either a Dipslide dip sample or a Dipslide stream sample in addition to this.

Parents were asked to return the specimens by first class post on the day of collection.

\section{Laboratory methods}

The length of time it took for the sample to reach the laboratory was noted.

Biochemical analysis for $\mathrm{pH}$, protein, blood, ketones, nitrites, and glucose was performed using Multistix (Ames). 
An aliquot of $50 \mu \mathrm{l}$ from each specimen was transferred into a microtitre tray using reverse pipetting. The urine was allowed to stand for 15 minutes and then examined using an inverted microscope. White blood cells, red blood cells, epithelial cells, casts, organisms, crystals, and amorphous debris were noted. Using a $1 \mu$ standard loop (Medical Wire and Equipment Co), urine was spread on to a quarter of a $9 \mathrm{~cm}$ petri dish containing cysteine lactose electrolyte deficient (CLED) agar (Lab M). This was incubated at $37^{\circ} \mathrm{C}$ aerobically overnight. The colony counts were evaluated and organisms identified by conventional methods.

Contamination was defined as any growth on the plate or Dipslide.

PART 2

A total of 171 MSSUs were collected and were cultured immediately. A $5 \mathrm{ml}$ aliquot of the remainder of each sample was put in a boric acid container and stored at room temperature. Samples were taken for culture from the boric acid specimens at 24 and 48 hours. The colony counts were compared with those of the fresh MSSUs

The $\chi^{2}$ test and the calculation of $\log$ odds ratios $^{9}$ were used for statistical analysis of the results.

\section{Results}

The parents of 107 children agreed to take part in the study. A boric acid sample and a Dipslide, dip or stream method, was received from 100 patients, a compliance of $93.5 \%$. In 16 of these children the initial MSSU was not sterile and they were excluded from further study. Thus there were 84 children with a sterile MSSU and both a boric acid and Dipslide sample. The results in this group of patients were further examined. There were 43 boys (age range 3-18 years, mean 8.9 years) and 41 girls (age range 2-15 years, mean $9 \cdot 1$ years); table 1 gives details of the diagnoses in these children.

The time taken to receive the specimens by first class post varied from one to seven days. The mean length of time to return was $1 \cdot 7$ days and modal length of time one day.

\section{DIPSLIDES}

Seventeen Dipslides were returned with one or both media detached (CLED, $n=13$; McConkey, $n=2$; both, $n=2$ ). These Dipslides could not be relied upon to exclude urinary tract

Table 1 Diagnoses of children in study

\begin{tabular}{lc}
\hline & $N o(\%)$ of children \\
\hline Urinary tract infection \\
Vesicoureteric reflux \\
Minimal change nephrotic syndrome & $30(36)$ \\
Other glomerulonephritis & $6(7)$ \\
Haematuria (miscellaneous) & $9(11)$ \\
Chronic renal failure & $9(11)$ \\
Henoch-Schönlein syndrome & $8(9)$ \\
Proteinuria (miscellaneous) & $6(7)$ \\
Other & $4(5)$ \\
Total & $12(14)$ \\
\hline
\end{tabular}

infection. A further 36 Dipslides were not sterile. Bacteriological details of the non-sterile Dipslides are given in table 2.

From the 84 Dipslides examined, 41 (20 girls, 21 boys) had been treated by the stream method and 38 (20 boys, 18 girls) by the dip method. The method of treatment of five (two boys and three girls) was not known. The difference between the dip and stream results in boys and girls by $\chi^{2}$ just reached significance $(p=0.05)$, although the relative risk of contamination as judged by the $\log$ odds ratio calculation were mean (SD) $0.91(0.644)$ for boys and 1.20 $(0.780)$ for girls, the weighted mean of these being $1.03(0.496)$. A comparison of the nonsterile Dipslides in the two groups is shown in table 3.

BORIC ACID

The results of the samples collected into boric acid were examined similarly and the results tabulated in table 4.

\section{BORIC ACID INHIBITION}

From the 171 urines examined 97 were culture positive. Nine $(9 \%)$ of these infected samples showed a reduced colony count after storage for 24 and 48 hours in boric acid.

In seven of the nine discrepant samples it was noted that the boric acid bottle was underfilled. The bacteriological results of the discrepant samples are given in table 5.

\section{Table 2 Non-sterile and technically unsatisfactory Dipslides}

\begin{tabular}{lc}
\hline Growth & No (\%) \\
\hline $\begin{array}{l}\text { (1) Indeterminable (culture medium } \\
\text { detatched) }\end{array}$ & $17(20)$ \\
(2) $>10^{5}$ Organisms/ml & $1(1)$ \\
Faecal flora & $2(2)$ \\
Two organisms & $4(5)$ \\
(3) $10^{3}-10^{5}$ Organisms/ml & $8(9)$ \\
Pure growth (any organism) & $7(8)$ \\
Faecal flora & $7(8)$ \\
Skin and faecal flora & $3(4)$ \\
Mixed skin flora & $4(5)$ \\
(4) Coliform Organisms/ml & $53(63)$ \\
Staphylococcus epidermidis & \\
\hline Total &
\end{tabular}

Table 3 Comparison of Dipslide methods. Results are mean $(S D)$

\begin{tabular}{llrl}
\hline & \multicolumn{3}{l}{ Non-sterile } \\
\cline { 2 - 4 } & Dip & \multicolumn{1}{l}{ Stream } & Unkown \\
\hline Boys & $13 / 20(65)$ & $9 / 21(43)$ & $2 / 2(100)$ \\
Girls & $15 / 18(83)$ & $12 / 20(60)$ & $2 / 3(67)$
\end{tabular}

Log odds ratio for boys $0.91(0.644)$ and for girls $1 \cdot 20(0.780)$; weighted mean $1.03(0.496) ; \chi^{2}$ test, $p=0.05$.

Table 4 Non-sterile boric acid samples

\begin{tabular}{ll}
\hline Growth & No (\%) \\
\hline (1) $>10^{5}$ Organisms/ml & $1(1)$ \\
Mixed faecal flora & $1(1)$ \\
(2) $10^{3}-10^{5}$ Organisms/ml & $2(2)$ \\
Coliform & $4(5)$ \\
Skin and faecal flora & $1(1)$ \\
Mixed skin flora & $9(10)$ \\
Mixed faecal flora & 9
\end{tabular}


Table 5 Anomalies in boric acid culture test $(\boldsymbol{n}=9)$

\begin{tabular}{llll}
\hline$M S S U$ result (organisms $/ m l)$ & 24 hours in boric acid & 48 hours in boric acid & Possible reason \\
\hline$>10^{5}$ Coliforms +candida & As MSSU & Candida only & $\mathrm{U}$ \\
$>10^{5}$ Coliforms & As MSSU & $10^{2}$ Coliforms & $\mathrm{U}$ \\
$<10^{5}$ Candida & As MSSU & No growth & $\mathrm{U}$ \\
$>10^{5}$ Coliforms & $10^{3}-10^{5}$ Coliforms & No growth & $\mathrm{U}$ \\
$>10^{5}$ Pseudomonas aeruginosa & No growth & $10^{3}$ Coliforms & $\mathrm{U}+++$ \\
$>10^{5}$ Coliforms & $10^{3}$ Coliforms & No growth & $\mathrm{U}$ \\
$<10^{5}$ Candida & As MSSU & $10^{2}$ Pseudomonas capacia & $\mathrm{U}$ \\
$>10^{5}$ Pseudomonas capacia & $10^{3}$ Pseudomonas capacia & $10^{3}$ Candida & Nothing obvious \\
$>10^{5}$ Candida & $10^{3}$ Candida & Nothing obvious \\
\hline
\end{tabular}

$\mathrm{U}=$ underfilled bottle. Bottles were underfilled if the initial specimen did not allow sufficient urine to fill the bottle.

\section{Discussion}

'I am still referred patients who have been given antibiotics without having had a urine culture taken beforehand. . . .' (White 1987). ${ }^{10}$ This is still a frequent scenario in many outpatient departments and a reliable and sufficiently robust method of collecting and transporting urine from the community to the hospital is clearly needed. Unfortunately, the results of this study show that there are problems with both Dipslides and boric acid collection. Interpretation of the results of the study depends to a large extent on the specific purpose of urine collection at home. As a screening test to identify symptomatic children who need a definitive urine culture (for example, a suprapubic sample) and to monitor children with vesicoureteric reflux, false positive urines, in small numbers, are less of a worry than false negative urines.

An unexpected but major problem with the Dipslides was the high rate of technical failure. Altogether $20 \%$ of the Dipslides were received with one or both media detatched; presumably this occurred during postal transit. They had been issued 24 hours previously and had been individually examined before issue.

If the conventional diagnostic level of $>10^{5}$ organisms $/ \mathrm{ml}$ is taken as defining urinary tract infection, ${ }^{11}$ any child with $<10^{5}$ organisms $/ \mathrm{ml}$ could be considered as non-infected. On this basis, three Dipslides, plus the 17 technically unsuccessful Dipslides and one boric acid sample would need to be repeated (table 2). It is not safe to assume that a bacterial count of $<10^{5}$ organisms $/ \mathrm{ml}$ is necessarily benign, however, because some children with infection may have such counts. ${ }^{12-14}$ Thus if Dipslides with growths between $10^{3}-10^{5}$ organisms $/ \mathrm{ml}$ are considered as equivocal, 33 more Dipslides would need to be repeated. In this case 36 Dipslides would have equivocal growth and 17 would need repeating for technical reasons, a total of $53(63 \%)$. Clearly, this is a far too high false positive rate for it to be a practical technique for the indentification of low bacterial count infection. If this limitation is accepted, however, Dipslides are a servicable home culture technique. The number of repeat Dipslides would be very considerably reduced if they were more robust. We did not attempt to assess the 'false negative' rate for Dipslides as we felt that inhibition of growth on the culture medium, provided the specimens were collected correctly, was unlikely to occur. To do so would require a similar study to that performed on the boric acid samples in part 2 of the study.
The situation with boric acid preservation is even more complex. On face value this method of preservation is much more reliable. Using the criterion of $>10^{5}$ organisms $/ \mathrm{ml}$, only one boric acid sample would need repeating. Using $>10^{3}$ organisms $/ \mathrm{ml}$ as a cut off point, a total of nine samples $(10 \%)$ would need to be repeated. The second part of the study, however, showed significant inhibition of bacterial growth in nine urine samples after prolonged incubation in boric acid. Seven of these nine samples were in bottles that had been underfilled because of an initial small sample. It is reasonable to assume that the increase in boric acid concentration due to underfilling was the reason for the bacterial inhibition. Two samples were in correctly filled bottles, however, and suggest that a degree of inhibition may occur even when the correct concentration of boric acid is used. If the possibilities of urinary tract infection with a low bacterial count and the risk of reduction in bacterial count by boric acid are accepted, it is probably wise to repeat any urine transported in boric acid that has any growth in it. It would also be necessary to repeat all samples in underfilled bottles, unless they yielded $>10^{5}$ organisms $/ \mathrm{ml}$. By emphasising to parents that a correct volume of urine was essential, repeat urine samples because of underfilling could be minimised. This would, thus, mean repeating more than $10 \%$ of these urines but would probably yield a very low false negative rate.

Urinary tract infections are still diagnosed too late to prevent irreversible renal damage in too many children. If we are to attempt to reduce the incidence of chronic pyelonephritis a reliable, simple diagnostic test for urinary tract infection for home use would be of great value. Dipslides, or similar home culture techniques, have great attractions and previous reports claim good agreement with MSSUs. Most of these studies have, however, been in an 'office' situation where a nurse has collected or supervised the collection of the urine sample. ${ }^{5}$ Our results suggest that these results cannot be reproduced when parents collect the urine unsupervised. In a previous study, comparing the two ways of using the Dipslide, there was a very low contamination rate using the Dipslide dip method collected under supervision and a higher contamination rate using the stream method unsupervised at home. ${ }^{7}$ Our results suggest that possibly there is less contamination using the stream method when both methods are compared under the same circumstances, although our results only just reach significance. The parents in our study were commit- 
ted people who agreed to take part in a research protocol. Their children were accustomed to producing MSSUs and they had individual tuition from the two nurses involved. This was supported by written instructions and the urines were collected within a few hours of the clinic visit. It is likely that in routine practice the contamination rates would be even higher.

We conclude that neither method is totally satisfactory and that the method chosen should be dictated by circumstance. We suggest that to exclude a urinary tract infection in an ill child, provided that the general practitioner is prepared to examine the result, Dipslides should be used. That way, a negative result can be obtained in 24 hours, without recourse to hospital. The child should be referred to hospital for an appropriate fresh sample to be taken if the Dipslide shows a growth. The Dipslide should also be sent, to provide antibiotic sensitivities and identification of the organism. For the follow up of at risk children, we prefer boric acid. The repeat rate for Dipslides under these circumstances is unacceptably high. It would be unreasonable to expect these children to attend hospital two out of three times that they sent in a sample and this would not only cause great anxiety but also doubtless diminished compliance in the long term.
Dr Jewkes is supported by a Children Nationwide Paediatric Research Fellowship.

We thank Dr RF Williams for the help and time of his staff in the bacteriology department, Royal Manchester Children's Hospital, in carrying out this study. We also thank staff nurse CL McGinty and state enrolled nurse M Cope for all their help in teaching parents and collecting urine samples.

1 Porter IA, Brodie J. Boric acid preservation of urine samples. Br Med F 1969;ii:353-5.

2 Watson PG, Duerdin BI. Laboratory assessment of physical and chemical methods of preserving urine specimens. f Clin Pathol 1977;30:532-6.

3 Matthews SCW. An evaluation of a new commercial urine transport system. Med Lab Sci 1987;44:341-4.

4 Mackey JP, Sandys GH. Laboratory diagnosis of infections of the urinary tract in general practice by means of a dip-

5 Arneil GC, McAllister TA, Kay P. Detection of bacteriuria at room temperature. Lancet 1970;i:119-21.

6 Arneil GC, McAllister TA, Kay P. Measurement of bacterirneil GC, McAllister TA, Kay P. Measurement of by plane dipslide culture. Lancet 1973;i:94-5.
iuria by

7 Edwards B, White RHR, Maxted H, Deverill I, White PA. Screening methods for covert bacteriuria in schoolgirls. $B$ Med f 1975;ii:463-5.

8 Asscher AW, Harvard Davis R, Mackenzie R. Dipslide diagnosis of urinary tract infection. Lancet 1977;ii:202.

9 Armitage P, Berry G. Relative risk. Statistical methods in medical research. Gloucester: Blackwell Scientific Productions, 1987:457-86.

10 White RHR. Management of urinary tract infection. Arch Dis Child 1987;62:421-7.

11 Kass EH. Bacteriuria and the diagnosis of infection of the urinary tract. Arch Intern Med 1975;100:709-14.

12 Pryles CV. The diagnosis of urinary tract infection. Pediatrics $1960 ; 26: 441-51$.

13 Glass J. Diagnosis of urinary tract infections. In: Postlethwaite RJ, ed. Clinical paediatric nephrology. Bristol: Wright, 1986:350-3

14 Ogra PL, Faden HS. Urinary tract infections in childhood an update. F Pediatr 1985;106:1023-33. 